\title{
Bronchial anastomotic complications following lung transplantation: still a major cause of morbidity?
}

\author{
R.A. Schmid*, A. Boehler\#, R. Speich\#, H-R. Frey\#, E.W. Russi\#, W. Weder*
}

Bronchial anastomotic complications following lung transplantation: still a major cause of morbidity? R.A. Schmid, A. Boehler, R. Speich, H-R. Frey, E.W. Russi, W. Weder. ABSTRACT: The frequency of bronchial anastomotic complications following lung transplantation has decreased in recent years, but continues to be a potential cause of morbidity and mortality.

We have, therefore, reviewed the results of 67 consecutive bronchial anastomoses at risk in 43 patients surviving more than 7 days following lung transplantation. The bronchial anastomoses were performed using a standardized technique, without direct or indirect revascularization. Regular triple immunosuppressive therapy was given, including prednisone $\left(0.5 \mathrm{mg} \cdot \mathrm{kg}^{-1}\right.$ daily $)$ starting on the day of surgery. Bronchial healing was graded using the Couraud classification. The median follow-up time was 14 months (range 1-45 months).

No major airway complications occurred. On 236 serial bronchoscopic examinations, no anastomotic stenoses were observed. One anastomosis showed limited focal necrosis $(2 \mathrm{~mm})$ (Couraud 3a), and two anastomoses had partial primary mucosal healing without necrosis (Couraud 2a). In all other anastomoses, primary mucosal healing (Couraud 1) was observed.

Carefully performed bronchial anastomosis according to the technique described enables reliable bronchial healing and yields a low complication rate. Additional measures, such as direct revascularization, forced telescoping, omentum wrap and interruption of steroid therapy, are not necessary.

Eur Respir J 1997; 10: 2872-2875.
*Dept of Surgery, Pulmonary Division, and $* *$ Dept of Internal Medicine, University Hospital, Zürich, Switzerland.

Correspondence: W. Weder

Dept of Surgery

University Hospital

Rämistr. 100

CH-8091 Zürich

Switzerland

Keywords: Bronchial anastomosis lung transplantation technique

Received: March 261997

Accepted after revision June 201997
In early experience of lung transplantation (19631978), dehiscence of the bronchial anastomosis was the major complication, occurring in 16 out of 20 patients who survived more than 7 days [1]. In the period from 1986 to 1989 , following en bloc double-lung transplantation $25 \%$ of the patients died due to ischaemic complications of the tracheal anastomosis [1]. Sequential single-lung transplantation with bilateral bronchial anastomosis and further technical improvements, as well as better preservation and postoperative management, reduced the incidence of ischaemic airway complications [2]. Bronchial complications with a mortality of $2-4 \%$ are still reported in $4-12 \%$ of lung transplant recipients [3, 4]. Various technical measures, such as reconstruction of the bronchial circulation [5], omental wrap [6] and other methods, have been proposed to improve healing of the donor bronchus.

The complications of bronchial anastomoses may be divided into early ( $<3$ months) and late ( $>3$ months) events; they include bronchial necrosis, dehiscence, excessive granulation tissue, malacia and stricture. Couraud proposed a classification of bronchial healing according to bronchoscopic findings [7].

We describe a technique of bronchial anastomosis that was not supplemented by protective measures and analyse our results, demonstrating no significant airway complications in a series of 67 consecutive bronchial anastomoses at risk.

\section{Patients and methods}

Seventy six bronchial anastomoses were performed in 48 lung transplant recipients at our institution between November 1992 and December 1996. Five patients died within 7 days after transplantation. All had normal anastomoses at autopsy. Thus, in the surviving 43 recipients, 67 anastomoses were at medium- to longterm risk of bronchial complications. The results were studied retrospectively.

The median age of the patients was 41 (range 21-59) yrs; 30 recipients were female and 13 male. The indications for lung transplantation were: cystic fibrosis $(\mathrm{n}=$ 9); chronic obstructive pulmonary disease (COPD)/emphysema $(n=10)$; cryptogenic pulmonary fibrosis $(n=9)$; primary pulmonary hypertension $(n=4)$; thromboembolic pulmonary hypertension $(\mathrm{n}=2)$; lymphangioleiomyomatosis $(n=4)$; bronchiectasis $(n=4)$; bronchiolitis obliterans (retransplantation) $(\mathrm{n}=1)$.

Nineteen patients underwent single-lung transplantation and 24 patients sequential, bilateral lung transplantation. The series included one retransplantation. 
Unilateral transplantation was performed five times on the left side and 14 times on the right side. The median ischaemic time was: in the unilateral group $3 \mathrm{~h} 20 \mathrm{~min}$ (range $2 \mathrm{~h}$ to $5 \mathrm{~h} 40 \mathrm{~min}$ ); in the bilateral group for the first lung $3 \mathrm{~h} 20 \mathrm{~min}$ (range $1 \mathrm{~h} 30 \mathrm{~min}$ to $5 \mathrm{~h} 15 \mathrm{~min}$ ); and in the bilateral group for the second lung $5 \mathrm{~h} 27 \mathrm{~min}$ (range $3 \mathrm{~h} 40 \mathrm{~min}$ to $7 \mathrm{~h}$ ).

The lungs were harvested using standard techniques. After injection of $500 \mu \mathrm{g}$ prostaglandin $\mathrm{E}_{1}$ (Prostin VR; Upjohn, Puurs, Belgium) into the pulmonary artery, the lungs were flushed with $4 \mathrm{~L}$ cold modified Euro-Collins solution and preserved moderately inflated with $100 \%$ oxygen at $4^{\circ} \mathrm{C}$.

The bronchial anastomosis was performed first. The recipient's main bronchus was divided one ring above the origin of the upper lobe bronchus. The bronchial arteries were ligated and no electrocautery was used for coagulation of the peribronchial tissue. All dissection on the bronchus was performed using a "minimal" or "no touch" technique. The donor bronchus was trimmed to a maximal length of only one half ring above the origin of the upper lobe bronchus. The membranous part was left $2-3 \mathrm{~mm}$ longer than the cartilaginous part. Absorbable suture material was used (Polydioxanon, PDA 4-0). A continuous suture to the membranous wall and end-to-end anastomosis with interrupted single stitches to the cartilaginous portion was performed. The first stitch to the cartilaginous portion was placed in the middle of the circumference to achieve optimal size matching. Forced telescoping of the anastomosis was avoided, and telescoping was employed only when it occurred spontaneously in the event of a donor-to-recipient size mismatch. The anastomosis was covered with peribronchial tissue to protect the pulmonary artery from erosion of the stitches, which can result in the development of a bronchopulmonary arterial fistula [3]. In the first three recipients of this series, the anastomosis was covered with omentum. Thereafter, this technique was abandoned. With the exception of the omentum wrap used in this very early practice, the technique did not change in all 76 anastomoses.

The patients received regular triple immunosuppressive therapy with cyclosporin A $8 \mathrm{mg} \cdot \mathrm{kg}^{-1}$ daily (Sandimmun; Sandoz Wander AG, Bern, Switzerland), azathioprine $2 \mathrm{mg} \cdot \mathrm{kg}^{-1}$ daily (Imurek; Wellcome AG, Reinach, Switzerland), and methylprednisone (Solu-Medrol; Upjohn, Brüttisellen, Switzerland). The initial dose of methylprednisone was $1,000 \mathrm{mg} i . v$. before reperfusion, followed by $500 \mathrm{mg}$ i.v. on the first postoperative day and $0.5 \mathrm{mg} \cdot \mathrm{kg}^{-1}$ daily (prednisone; Galepharm, Küsnacht, Switzerland) as a maintenance dose. Rejection episodes were treated with pulsed steroid doses of $1,000 \mathrm{mg}$, and the methylprednisone maintenance dose was increased to $1 \mathrm{mg} \cdot \mathrm{kg}^{-1}$ daily.

Flexible bronchoscopy was performed on the first postoperative day, with follow-up examinations together with transbronchial surveillance biopsy every 3-4 weeks for the first 6 months. Thereafter, the patients were examined every 3-6 months. This rigorous surveillance protocol was applied to all patients as reported previously [8]. In total, 236 bronchoscopies were performed. Bronchial secretions were collected from the area of the anastomosis. Itraconazole $200 \mathrm{mg} \cdot \mathrm{day}^{-1}$ was given routinely if Aspergillus sp. was detected in bronchial secretions or bronchoalveolar lavage fluid.

Bronchial healing was assessed according to the classification of Couraud as follows: Grade 1 - complete primary mucosal healing; Grade $2 \mathrm{a}$ - complete primary healing without necrosis, partial primary mucosal healing; Grade 2b - complete primary healing without necrosis, no primary mucosal healing; Grade 3a - limited focal necrosis (extending less than $5 \mathrm{~mm}$ from the anastomotic line); and Grade 3b - extensive necrosis.

\section{Statistical analysis}

All data are expressed as median (range). The significance of differences between groups was determined using the Mann-Whitney U-test for continuous variables and the Fisher exact test for discrete variables. A p-value equal to or greater than 0.05 was considered not significant.

\section{Results}

Median follow-up time was 14 months (range 1-45 months). No severe airway complications occurred and no bronchial stenosis was detected in any patient. Three localized dehiscences $(6 \%)$ at the posteromedial portion of the recipient main bronchus were observed (table 1). They were classified as Couraud grade $2 \mathrm{a}$ on two occasions and Couraud grade $3 \mathrm{a}$ on one. The time of diagnosis was 2, 4 and 6 months postoperatively. The age of the patient was not related to the occurrence of bronchial complications $(\mathrm{p}=0.12)$.

None of the dehiscent anastomoses had to be treated by a stent or by operative revision. Spontaneous healing was observed in both 2 a dehiscences within 3 months. The third patient with a Couraud 3 a complication died of Aspergillus infection unrelated to the airway complication.

The ischaemic times of the lung grafts in which dehiscence occurred were between 3.5 and $4.5 \mathrm{~h}$, and not different from the grafts with primary bronchial healing. There was no statistical difference in the number of rejection episodes between patients with and without dehiscence (table 2).

In $10-15 \%$ of the patients, fibrinous membranes were detected at the site of the anastomosis and Aspergillus $\mathrm{sp}$. was found in the bronchial secretions. After initiation of treatment with oral itraconazole, the membranes disappeared in all cases within 2 months.

Table 1. - Bronchial anastomotic complications

\begin{tabular}{lccccc}
\hline $\begin{array}{l}\text { Pt } \\
\text { No. }\end{array}$ & Diagnosis & $\begin{array}{c}\text { Type of } \\
\text { treatment }\end{array}$ & $\begin{array}{c}\text { Ischaemic time } \\
\mathrm{h}\end{array}$ & Side & $\begin{array}{c}\text { Couraud } \\
\text { class }\end{array}$ \\
\hline 1 & BECT & Bilateral & 3.0 & Right & $2 \mathrm{a}$ \\
2 & CF & Bilateral & 4.5 & Left & $2 \mathrm{a}$ \\
3 & PPH & Bilateral & 3.5 & Right & 25 \\
\hline
\end{tabular}

Pt: patient; BECT: bronchiectasis; CF: cystic fibrosis; PPH: primary pulmonary hypertension. 
Table 2. - Rejection episodes in patients with and without bronchial dehiscence

\begin{tabular}{|c|c|c|c|}
\hline & $\begin{array}{c}\text { With } \\
\text { dehiscence } \\
(\mathrm{n}=3)\end{array}$ & $\begin{array}{l}\text { Without } \\
\text { dehiscence } \\
(\mathrm{n}=40)\end{array}$ & p-value \\
\hline $\begin{array}{l}\text { AR clinically } \\
\text { (per patient) }\end{array}$ & $\begin{array}{c}4 \\
(1.33)\end{array}$ & $\begin{array}{l}27 \\
(0.68)\end{array}$ & $0.11^{+}$ \\
\hline $\begin{array}{l}\mathrm{AR} \geq \mathrm{A} 2 \text { histologically } \\
\text { (per patients) }\end{array}$ & $\begin{array}{c}3 \\
(1.0)\end{array}$ & $\begin{array}{c}26 \\
(0.65)\end{array}$ & $0.38^{+}$ \\
\hline $\begin{array}{l}\text { Total AR } \\
\text { (per patient) }\end{array}$ & $\begin{array}{c}7 \\
(2.33)\end{array}$ & $\begin{array}{c}53 \\
(1.32)\end{array}$ & $0.16^{+}$ \\
\hline BOS & 1 & 5 & $0.34^{\dagger}$ \\
\hline
\end{tabular}

AR: acute rejection; A2: histologically mild acute rejection according to the criteria of the International Society for Heart and Lung Transplantation; BOS: bronchiolitis obliterans syndrome. ${ }^{+}$: Mann-Whitney U-test; ${ }^{\dagger}$ : Fisher exact test.

\section{Discussion}

Our data demonstrate a very low incidence of airway complications following lung transplantation in 67 consecutive bronchial anastomoses. There was no death due to bronchial anastomotic complications and no bronchial stenosis occurred. Only three instances of localized bronchial dehiscence were observed and none required bronchial stenting or surgical intervention.

The Washington University Group evaluated 348 bronchial anastomoses in lung transplant recipients from 1988 to 1994 . The airway complication rate in this series dropped from $11 \%$ in the first 77 patients to $4 \%$ in the last 76 transplants [4]. WILson et al. [10] recently reported an incidence of severe airway complications as low as $1.6 \%$ in 100 consecutive anastomoses. In their study, the airway complication rate was not related to the use of steroids, the preoperative diagnosis or the presence of a wrap with pericardium or omentum.

The development of sequential, bilateral, single-lung transplantation reduced the incidence of severe airway complications to less than $10 \%$. Based on their early experience, the Toronto Lung Transplant Group reported that eliminating high-dose steroids in the initial immunosuppressive treatment [11] and wrapping of the bronchial anastomosis with omentum improved bronchial healing [6]. Subsequently, other technical modifications of the bronchial anastomosis aimed at improving vascularization of the donor bronchus have been evaluated. These include internal mammary artery pedicles [12] and intercostal muscle flaps [12, 13]. It has been shown that these tissue wraps induce indirect bronchial revascularization within a few days after transplantation. However, experimental studies have demonstrated that reliable bronchial healing occurs without wrapping [14], and in randomized clinical trials the use of tissue wraps has failed to improve bronchial healing after singlelung transplantation $[15,16]$.

Telescoping of the bronchial anastomoses was introduced into clinical practice by the San Antonio group in 1991 [17]. In a series of 164 consecutive anostomoses using this method, the Pittsburgh group reduced the frequency of bronchial complications from 32 to $12 \%$ [18]. However, recent studies have indicated that the telescoped anastomosis favours stenotic complications [19].
Since the inception of our lung transplant programme, we have not used the telescoping technique. This may, in part, explain why we have not yet observed a stenosis. Indeed, ANDERSOn et al. [19] reported an incidence of airway stenosis of $7 \%$ with telescoping. Interestingly, a majority of these patients suffered from cystic fibrosis. After abandoning this technique, the authors subsequently observed no dehiscence or stenosis in 50 anastomoses.

Modification of the immunosuppressive regimen by avoiding the use of high-dose steroids in the early phase after transplantation has not reduced airway complications in lung graft recipients [20], and high-dose corticosteroids were not detrimental to bronchial healing in canine lung allografts $[14,21]$.

The most reasonable way to reduce donor bronchus ischaemia is, of course, direct bronchial artery revascularization. This technique has been reported in small series [5]. However, the effectiveness of bronchial recirculation in reducing airway complications remains to be proven. In experimental animal models, bronchial arterial circulation was already restored 4 weeks after transplantation [22, 23].

An interesting approach to increase immediate retrograde perfusion to the donor bronchus was published by SCHÄFERS et al. [20]. The authors demonstrated that the combined parenteral administration of heparin, prostaglandin $\mathrm{I}_{2}\left(\mathrm{PGI}_{2}\right)$ and prednisolone decreased the incidence of ischaemic bronchial complications of lung grafts. Additionally, reduction of reperfusion injury and improvement of preservation techniques may contribute to a reduced airway complication rate by improving retrograde perfusion to the donor bronchus. Furthermore, early observations have already indicated that the donor bronchus has to be trimmed as short as possible to improve retrograde blood supply [24, 25].

In the present series, ischaemic time or the number of episodes of acute rejection was not related to the occurrence of bronchial complications. It seems that, in addition to inadequate organ preservation, prolonged mechanical ventilation, positive end-expiratory pressure (PEEP) ventilation, systemic hypotension, and acute rejection, one of the most important factors in reducing complications of bronchial anastomosis is a careful surgical technique. The low airway complication rate in the present series may also indicate that direct bronchial revascularization is not needed for reliable bronchial healing.

In conclusion, our results demonstate that with the current technique bronchial anastomosis in lung transplantation can be performed safely with very satisfactory results.

\section{References}

1. Cooper JD. The evolution of techniques and indications for lung transplantation. Ann Surg 1990; 212: 250-256.

2. Noirclerc MJ, Metras D, Vaillant A, et al. Bilateral bronchial anastomosis in double-lung and heart-lung transplantations. Eur J Cardiothorac Surg 1990; 99: 14-21.

3. Shennib H, Massard G. Airway complications in lung transplantation. Ann Thorac Surg 1994; 57: 506-511.

4. Date H, Trulock EP, Arcidi JM, Sundaresan S, Cooper 
JD, Patterson GA. Improved airway healing after lung transplantation: an analysis of 348 bronchial anastomoses. J Thorac Cardiovasc Surg 1995; 110: 1424-1432.

5. Norgaard MA, Olsen PS, Svendsen UG, Pettersson G. Revascularization of the bronchial arteries in lung transplantation: an overview. Ann Thorac Surg 1996; 62: 1215-1221.

6. Dubois P, Choiniere L, Cooper JD. Bronchial omentopexy in canine lung allotransplantation. Ann Thorac Surg 1984; 38: 211-214.

7. Couraud L, Nashef SAM, Nicolini O, Jougon J. Classification of airway anastomotic healing. Eur $J$ Cardiothorac Surg 1992; 6: 496-497.

8. Boehler A, Vogt P, Zollinger A, Weder W, Speich R. Prospective study of the value of transbronchial lung biopsy after lung transplantation. Eur Respir J 1996; 9: 658-662.

9. Lung Rejection Study Group. Revision of the 1990 Working Formulation for the Classification of Allograft. Heart Lung Transplant 1996; 15: 1-15.

10. Wilson IC, Hasan A, Healey M, et al. Healing of the bronchus in pulmonary transplantation. Eur J Cardiothorac Surg 1996; 10: 521-527.

11. Lima O, Cooper JD, Peters WJ, et al. Effects of methylprednisolone and azathioprine on bronchial healing following lung transplantation. J Thorac Cardiovasc Surg 1981; 82: 211-215.

12. Turrentine MW, Kesler KA, Wright CD, et al. Effect of omental, intercostal, and internal mammary artery pedicle wraps on bronchial healing. Ann Thorac Surg 1990; 49: 574-579.

13. Rendina EA, Venuta F, Ricci P, et al. Protection and revascularization of bronchial anastomoses by the intercostal pedicle flap. J Thorac Cardiovasc Surg 1994; 107: 1251-1254.

14. Auteri JS, Jeevanandam V, Sanchez JA, Marboe CC, Kirby TJ Smith CR. Normal bronchial healing without bronchial wrapping in canine lung transplantation. Ann Thorac Surg 1992; 53: 80-84.

15. Miller JD, DeHoyos A. An evaluation of the role of omentopexy and of early perioperative corticosteroid administration in clinical lung transplantation. $J$ Thorac Cardiovasc Surg 1993; 105: 247-252.

16. Khaghani A, Tadjkarimi S, Al-Kattan K, et al. Wrapping the anastomosis with omentum or an internal mammary artery pedicle does not improve bronchial healing after single lung transplantation: results of a randomized clinical trial. J Heart Lung Transplant 1994; 13: 767-773.

17. Calhoon JH, Grover FL, Gibbons WJ, et al. Single lung transplantation. Alternative indications and technique. $J$ Thorac Cardiovasc Surg 1991; 101: 816-825.

18. Griffith BP, Magee MJ, Gonzalez IF, et al. Anastomotic pitfalls in lung transplantation. J Thorac Cardiovasc Surg 1994; 107: 743-754.

19. Anderson MB. Kriett JM, Harrell J, et al. Techniques for bronchial anastomosis. J Heart Lung Transplant 1995; 14: 1090-1094.

20. Schäfers HJ, Haverich A, Wagner TO, Wahlers T, Alken A, Borst HG. Decreased incidence of bronchial complications following lung transplantation. Eur $J$ Cardiothorac Surg 1992; 6: 174-179.

21. Pinsker KL, Veith FJ, Kamholz SL, Montefusco C, Emeson E, Hagstorm JWC. Influence of bronchial circulation and corticosteroid therapy on bronchial anastomotic healing. J Thorac Cardiovasc Surg 1984; 87 : 439-444.

22. Pearson FG, Goldberg M, Stone RM, Colapinto RF. Bronchial arterial circulation restored after reimplantation of canine lung. Can J Surg 1970; 13: 234-250.

23. Siegelman SS, Hagstorm JWC, Koerner SK, Veith FJ. Restoration of bronchial artery circulation after canine lung allotransplantation. J Thorac Cardiovasc Surg 1977; 73: 792-795.

24. Toronto Lung Transplant Group. Unilateral lung transplantation for pulmonary fibrosis. N Engl J Med 1986; 314: 1140-1145.

25. Pinsker KL, Koerner SK, Kamholz SL, Hagstrom JW, Veith FJ. Effect of donor bronchial length on healing: a canine model to evaluate bronchial anastomotic problems in lung transplantation. J Thorac Cardiovasc Surg 1979; 77: 669-673. 